\title{
Perception of Resources Spent on Defensive Medicine and History of Being Sued Among Hospitalists: Results from a National Survey
}

\author{
Sanjay Saint, MD, MPH', ${ }^{1,2,3}$, Valerie M. Vaughn MD, MSc1,2,3, Vineet Chopra, MD, MSc ${ }^{1,2,3}$, \\ Karen E. Fowler, $\mathrm{MPH}^{1,3}$, Allen Kachalia, MD, JD
}

${ }^{1}$ Center for Clinical Management Research, VA Ann Arbor Healthcare System, Ann Arbor, Michigan; ${ }^{2}$ Institute for Health Policy and Innovation \& Department of Internal Medicine, University of Michigan, Ann Arbor, Michigan; ${ }^{3}$ The Patient Safety Enhancement Program, University of Michigan and VA Ann Arbor Health System, Ann Arbor, Michigan; ${ }^{2}$ Department of Medicine, Brigham \& Women's Hospital, Harvard Medical School, Boston, Massachusetts.

The United States spends substantially more per capita for healthcare than any other nation. Defensive medicine is 1 source of such spending, but its extent is unclear. Using a national survey of approximately 1500 US hospitalists, we report the estimates the US hospitalists provided of the percent of resources spent on defensive medicine and correlates of their estimates. We also ascertained how many reported being sued. Sixty-eight percent of eligible recipients responded. Overall, respondents estimated that $37.5 \%$ of healthcare costs are due to defensive medicine. Just over $25 \%$ of our respondents, including $55 \%$ of those in practice for 20 years or more, reported being sued for medical malpractice. Veterans Affairs (VA) hospital affiliation, more years practicing as a physician, being male, and being a non-Hispanic white individual were all independently associated with decreased estimates of resources spent for defensive medicine. Journal of Hospital Medicine 2018;13:26-29. Published online first August 23, 2017. (C) 2018 Society of Hospital Medicine

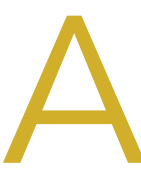

nnual healthcare costs in the United States are over $\$ 3$ trillion and are garnering significant national attention. ${ }^{1}$ The United States spends approximately 2.5 times more per capita on healthcare when compared to other developed nations. ${ }^{2}$ One source of unnecessary cost in healthcare is defensive medicine. Defensive medicine has been defined by Congress as occurring "when doctors order tests, procedures, or visits, or avoid certain high-risk patients or procedures, primarily (but not necessarily) because of concern about malpractice liability." ${ }^{3}$

Though difficult to assess, in 1 study, defensive medicine was estimated to cost $\$ 45$ billion annually. ${ }^{4}$ While general agreement exists that physicians practice defensive medicine, the extent of defensive practices and the subsequent impact on healthcare costs remain unclear. This is especially true for a group of clinicians that is rapidly increasing in number: hospitalists. Currently, there are more than 50,000 hospitalists in the United States, ${ }^{5}$ yet the prevalence of defensive medicine in this relatively new specialty is unknown. Inpatient care is complex and time constraints can impede establishing an optimal therapeutic relationship with the patient, potentially raising liability fears. We therefore sought to quantify hospitalist physician es-

\footnotetext{
*Address for correspondence and reprint requests: Sanjay Saint, MD, MPH, Chief of Medicine, VA Ann Arbor Healthcare System, George Dock Professor of Medicine, University of Michigan, 2800 Plymouth Road, Building 16, Room 430W, Ann Arbor, MI 48109; Telephone: (734) 615-8341; Fax: 734-936-8944; E-mail: saint@med.umich.edu
}

Received: February 10, 2017; Revised: May 4, 2017;

Accepted: May 19, 2017

2018 Society of Hospital Medicine DOI 10.12788/jhm.2800 timates of the cost of defensive medicine and assess correlates of their estimates. As being sued might spur defensive behaviors, we also assessed how many hospitalists reported being sued and whether this was associated with their estimates of defensive medicine.

\section{METHODS}

\section{Survey Questionnaire}

In a previously published survey-based analysis, we reported on physician practice and overuse for 2 common scenarios in hospital medicine: preoperative evaluation and management of uncomplicated syncope. ${ }^{6}$ After responding to the vignettes, each physician was asked to provide demographic and employment information and malpractice history. In addition, they were asked the following: In your best estimation, what percentage of healthcare-related resources (eg, hospital admissions, diagnostic testing, treatment) are spent purely because of defensive medicine concerns? $\%$ resources

\section{Survey Sample \& Administration}

The survey was sent to a sample of 1753 hospitalists, randomly identified through the Society of Hospital Medicine's (SHM) database of members and annual meeting attendees. It is estimated that almost $30 \%$ of practicing hospitalists in the United States are members of the SHM. ${ }^{5}$ A full description of the sampling methodology was previously published. ${ }^{6}$ Selected hospitalists were mailed surveys, a $\$ 20$ financial incentive, and subsequent reminders between June and October 2011.

The study was exempted from institutional review board review by the University of Michigan and the VA Ann Arbor Healthcare System. 
TABLE. Multivariable Regression Results: Variables Associated with Estimated Spending on Defensive Medicine

\begin{tabular}{lcc}
\hline Variable & $\begin{array}{c}\text { Adjusted Mean Estimated Resources } \\
\text { Spent on Defensive Medicine }\end{array}$ & $\begin{array}{c}\text { Mean Difference in Estimated Resources } \\
\text { Spent on Defensive Medicine }\end{array}$ \\
\hline VA affiliated & $32.2 \%$ & $-5.5 \%$ \\
non-VA affiliated & $37.7 \%$ & $-2.9 \%$ \\
\hline Mean years practicing (+10 years) & -- & .025 \\
\hline Employed by private group & $38.8 \%$ & $2.2 \%$ \\
$\quad$ Paid by self or hospital & $36.7 \%$ & $-2.6 \%$ \\
\hline Insurance paid by employer group & $35.7 \%$ & .235 \\
$\quad$ Paid by self or hospital & $38.3 \%$ & $-0.6 \%$ \\
\hline Personally been sued for medical malpractice & $37.8 \%$ & .141 \\
$\quad$ Never been sued for medical malpractice & $37.2 \%$ & $-3.0 \%$ \\
\hline Male & $36.4 \%$ & .670 \\
$\quad$ Female & $39.4 \%$ & $-12.2 \%$ \\
\hline Non-Hispanic white & $32.5 \%$ & .023 \\
$\quad$ All others & $44.7 \%$ & $<.001$ \\
\hline
\end{tabular}

aParameter estimates from linear regression.

\section{Variables}

The primary outcome of interest was the response to the "\% resources" estimated to be spent on defensive medicine. This was analyzed as a continuous variable. Independent variables included the following: VA employment, malpractice insurance payer, employer, history of malpractice lawsuit, sex, race, and years practicing as a physician.

\section{Statistical Analysis}

Analyses were conducted using SAS, version 9.4 (SAS Institute). Descriptive statistics were first calculated for all variables. Next, bivariable comparisons between the outcome variables and other variables of interest were performed. Multivariable comparisons were made using linear regression for the outcome of estimated resources spent on defensive medicine. A $P$ value of $<.05$ was considered statistically significant.

\section{RESULTS}

Of the 1753 surveys mailed, 253 were excluded due to incorrect addresses or because the recipients were not practicing hospitalists. A total of 1020 were completed and returned, yielding a $68 \%$ response rate (1020 out of 1500 eligible). The hospitalist respondents were in practice for an average of 11 years (range 1-40 years). Respondents represented all 50 states and had a diverse background of experience and demographic characteristics, which has been previously described. ${ }^{6}$

\section{Resources Estimated Spent on Defensive Medicine} Hospitalists reported, on average, that they believed defensive medicine accounted for $37.5 \%$ (standard deviation, 20.2\%) of all healthcare spending. Results from the multivariable regression are presented in the Table. Hospitalists affiliated with a VA hospital reported $5.5 \%$ less in resources spent on defensive medicine than those not affiliated with a VA hospital (32.2\% VA vs $37.7 \%$ non-VA, $P=.025)$. For every 10 years in practice, the estimate of resources spent on defensive medicine decreased by $3 \%(P=.003)$. Those who were male $(36.4 \%$ male vs $39.4 \%$ female, $P=.023$ ) and non-Hispanic white (32.5\% non-Hispanic white vs $44.7 \%$ other, $P \leq .001$ ) also estimated less resources spent on defensive medicine. We did not find an association between a hospitalist reporting being sued and their perception of resources spent on defensive medicine.

\section{Risk of Being Sued}

Over a quarter of our sample (25.6\%) reported having been sued at least once for medical malpractice. The proportion of hospitalists that reported a history of being sued generally increased with more years of practice (Figure). For those who had been in practice for at least 20 years, more than half (55\%) had been sued at least once during their career.

\section{DISCUSSION}

In a national survey, hospitalists estimated that almost $40 \%$ of all healthcare-related resources are spent purely because of defensive medicine concerns. This estimate was affected by personal demographic and employment factors. Our second major finding is that over one-quarter of a large random sample of hospitalist physicians reported being sued for malpractice.

Hospitalist perceptions of defensive medicine varied significantly based on employment at a VA hospital, with VA-affiliated hospitalists reporting less estimated spending on defensive medicine. This effect may reflect a less litigious environment within the VA, even though physicians practicing within the VA can be reported to the National Practitioner Data Bank. ${ }^{7}$ The different environment may be due to the VA's patient mix (VA 


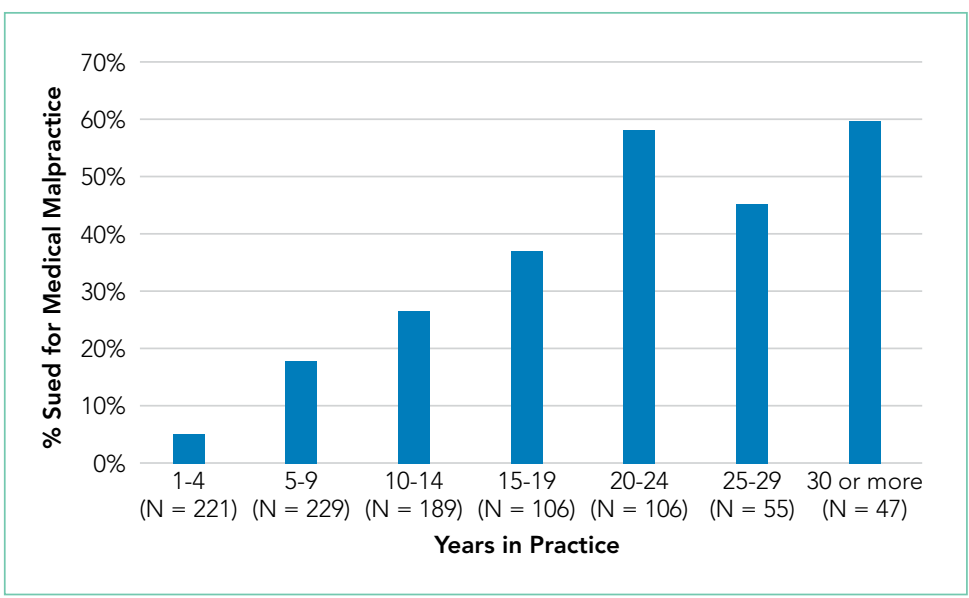

FIG. Proportion of hospitalists that have personally been sued by years in practice.

responses to spending on defensive medicine may not represent actual practice. Third, we did not confirm details such as place of employment or history of lawsuit, and this may be subject to recall bias. However, physicians are unlikely to forget having been sued. Finally, this survey is observational and cross-sectional. Our data imply association rather than causation. Without longitudinal data, it is impossible to know if years of practice correlate with perceived defensive medicine spending due to a generational effect or a longitudinal effect (such as more confidence in diagnostic skills with more years of practice).

Despite these limitations, our survey has important policy implications. First, we found that defensive medicine is perceived by hospitalists to be costly. Although physicians likely overestimated the cost (37.5\%, or an estimated $\$ 1$ trillion is far higher than previous estimates of approximately $2 \%$ of all healthcare spend-

patients tend to be poorer, older, sicker, and have more mental illness) ${ }^{8}$; however, it could also be due to its de facto practice of a form of enterprise liability, in which, by law, the VA assumes responsibility for negligence, sheltering its physicians from direct liability.

We also found that the higher the number of years a hospitalist reported practicing, the lower the perception of resources being spent on defensive medicine. The reason for this finding is unclear. There has been a recent focus on high-value care and overspending, and perhaps younger hospitalists are more aware of these initiatives and thus have higher estimates. Additionally, non-Hispanic white male respondents estimated a lower amount spent on defensive medicine compared with other respondents. This is consistent with previous studies of risk perception which have noted a "white male effect" in which white males generally perceive a wide range of risks to be lower than female and non-white individuals, likely due to sociopolitical factors. ${ }^{9}$ Here, the white male effect is particularly interesting, considering that male physicians are almost 2.5 times as likely as female physicians to report being sued. ${ }^{10}$

Similar to prior studies, ${ }^{11}$ there was no association with personal liability claim experience and perceived resources spent on defensive medicine. It is unclear why personal experience of being sued does not appear to be associated with perceptions of defensive medicine practice. It is possible that the fear of being sued is worse than the actual experience or that physicians believe that lawsuits are either random events or inevitable and, as a result, do not change their practice patterns.

The lifetime risk of being named in a malpractice suit is substantial for hospitalists: in our study, over half of hospitalists in practice for 20 years or more reported they had been sued. This corresponds with the projection made by Jena and colleagues, ${ }^{12}$ which estimated that $55 \%$ of internal medicine physicians will be sued by the age of 45 , a number just slightly higher than the average for all physicians.

Our study has important limitations. Our sample was of hospitalists and therefore may not be reflective of other medical specialties. Second, due to the nature of the study design, the ing) ${ }_{1}^{4}$ it also demonstrates the extent to which physicians feel as though the medical care that is provided may be unnecessary. Second, at least a quarter of hospitalist physicians have been sued, and the risk of being named as a defendant in a lawsuit increases the longer they have been in clinical practice.

Given these findings, policies aimed to reduce the practice of defensive medicine may help the rising costs of healthcare. Reducing defensive medicine requires decreasing physician fears of liability and related reporting. Traditional tort reforms (with the exception of damage caps) have not been proven to do this. And damage caps can be inequitable, hard to pass, and even found to be unconstitutional in some states. ${ }^{13}$ However, other reform options hold promise in reducing liability fears, including enterprise liability, safe harbor legislation, and health courts. ${ }^{13}$ Finally, shared decision-making models may also provide a method to reduce defensive fears as well. ${ }^{6}$

\section{Acknowledgments}

The authors thank the Society of Hospital Medicine, Dr. Scott Flanders, Andrew Hickner, and David Ratz for their assistance with this project.

Disclosure: The authors received financial support from the Blue Cross Blue Shield of Michigan Foundation, the Department of Veterans Affairs Health Services Research and Development Center for Clinical Management Research, the University of Michigan Specialist-Hospitalist Allied Research Program, and the Ann Arbor University of Michigan VA Patient Safety Enhancement Program.

Disclaimer: The views expressed in this article are those of the authors and do not necessarily reflect the position or policy of Blue Cross Blue Shield of Michigan Foundation, the Department of Veterans Affairs, or the Society of Hospital Medicine.

\section{References}

1. Centers for Medicare \& Medicaid Services. National Health Expenditures 2014 Highlights. 2015; https://www.cms.gov/Research-Statistics-Data-and-Systems/Statistics-Trends-and-Reports/NationalHealthExpendData/ NationalHealthAccountsHistorical.html. Accessed July 28, 2016.

2. OECD. Health expenditure per capita. Health at a Glance 2015. Paris: OECD Publishing; 2015.

3. U.S. Congress, Office of Technology Assessment. Defensive Medicine and Medical Malpractice. Washington, DC: U.S. Government Printing Office; July 1994. OTA-H-602. 
4. Mello MM, Chandra A, Gawande AA, Studdert DM. National costs of the medical liability system. Health Aff (Millwood). 2010;29(9):1569-1577.

5. Society of Hospital Medicine. Society of Hospital Medicine: Membership. 2017; http://www.hospitalmedicine.org/Web/Membership/Web/ Membership/Membership_Landing_Page.aspx?hkey $=97 \mathrm{f} 40 \mathrm{c} 85$-fdcd-411f-b3f6-e617bc38a2c5. Accessed January 5, 2017.

6. Kachalia A, Berg A, Fagerlin A, et al. Overuse of testing in preoperative evaluation and syncope: a survey of hospitalists. Ann Intern Med. 2015;162(2):100-108.

7. Pugatch MB. Federal tort claims and military medical malpractice. J Legal Nurse Consulting. 2008;19(2):3-6.

8. Eibner C, Krull H, Brown K, et al. Current and projected characteristics and unique health care needs of the patient population served by the Department of Veterans Affairs. Santa Monica, CA: RAND Corporation; 2015.
9. Finucane ML, Slovic P, Mertz CK, Flynn J, Satterfield TA. Gender, race, and perceived risk: the 'white male' effect. Health, Risk \& Society. 2000;2(2): 159-172.

10. Unwin E, Woolf K, Wadlow C, Potts HW, Dacre J. Sex differences in medico-legal action against doctors: a systematic review and meta-analysis. BMC Med. 2015:13:172.

11. Glassman PA, Rolph JE, Petersen LP, Bradley MA, Kravitz RL. Physicians' personal malpractice experiences are not related to defensive clinical practices. $J$ Health Polit Policy Law. 1996;21(2):219-241.

12. Jena $A B$, Seabury $S$, Lakdawalla $D$, Chandra A. Malpractice risk according to physician specialty. N Engl J Med. 2011;365(7):629-636.

13. Mello MM, Studdert DM, Kachalia A. The medical liability climate and prospects for reform. JAMA. 2014;312(20):2146-2155 